\author{
${ }^{\dagger}$ Seung-Soo Kim \\ ${ }^{\dagger}$ In-Sung Yeo \\ Shin-Jae Lee \\ Dae-Joon Kim \\ Brian Myeongwoo Jang \\ Soo-Hwan Kim \\ Jung-Suk Han
}

\section{Clinical use of alumina-toughened zirconia abutments for implant- supported restoration: prospective cohort study of survival analysis}

Authors' affiliations:

Seung-Soo Kim, School of Dentistry, Seoul

National University, Seoul, Korea,

In-Sung Yeo, Department of Prosthodontics, School of Dentistry and Dental Research Institute, Seoul

National University, Seoul, Korea,

Shin-Jae Lee, Department of Orthodontics, School

of Dentistry and Dental Research Institute, Seoul

National University, Seoul, Korea,

Dae-Joon Kim, Department of Advanced Materials

Engineering, Sejong University, Seoul, Korea,

Brian Myeongwoo Jang, Pre-doctoral Prosthodontic

Education, Harvard School of Dental Medicine,

Boston, MA, USA,

Soo-Hwan Kim, Department of Statistics, Korea

University, Seoul, Korea,

Jung-Suk Han, Department of Prosthodontics,

School of Dentistry and Dental Research Institute,

Seoul National University, Seoul, Korea,

Corresponding author:

Professor Jung-Suk Han

Department of Prosthodontics, School of Dentistry,

Seoul National University

28, Yeongeon-dong, Jongno-gu

Seoul, 110-749, South Korea

Tel.: +82 220722661

Fax: +82220723860

e-mail: proshan@snu.ac.kr

Key words: survival analysis, alumina-toughened zirconia abutment, implant-supported fixed restoration, type of prosthesis

\begin{abstract}
Objectives: The aim of this prospective cohort study was to compute the long-term clinical survival and complication rates of alumina-toughened zirconia abutments used for implant-supported restorations and to evaluate the effects of several clinical variables on these rates.

Material and methods: From May 1998 to September 2010, 213 patients aged 18 years or older were recruited. The patients received 611 external hex implants and 328 implant-supported fixed restorations using alumina-toughened zirconia abutments. During the follow-up, each restoration was coded as a dental event, which included loosening or fracture of abutment screws, and abutment fracture. From the coded data, the effects of the investigated clinical variables - restored area (anterior/posterior), number of prosthodontic units (one/two units or over), prosthesis type (single-unit/multiunit without pontic/multiunit with pontic), implant system, and patient genderon the survival of the abutments were evaluated. Survival analysis using Kaplan-Meier method and Cox proportional hazard model was applied. The 5-year survival and complication rates of the abutments were assessed.

Results: The number of prosthodontic units and the type of prosthesis had a significant association with complication rates $(P<0.05)$. Kaplan-Meier survival analysis estimated that the cumulative 5 -year complication rate of the abutments used in single restorations was $19.7 \%$. Multiunit-fixed dental prostheses without and with pontics had complication rates of $3.9 \%$ and $3.8 \%$, respectively. The 5-year survival rate of the abutments was more than $95 \%$, regardless of the type of prosthesis. Conclusions: Alumina-toughened zirconia abutments are likely to exhibit excellent long-term survival in clinical use for fixed restorations. Single tooth replacement with the abutment at the molar region may require special care and extra attention.
\end{abstract}

Titanium has been established as the material of choice for implant reconstruction due to its well-documented biocompatibility and mechanical properties (Adell et al. 1981). Clinical studies have documented superior survival rates for fixed implant restorations supported by titanium abutments (Andersson 1995). However, in a recent systematic review, certain complications were associated with metal abutments supporting fixed implant restorations (Pjetursson et al. 2007). One of the major issues noted was aesthetic concern. A previous meta-analysis showed more frequent aesthetic complications at metal abutments than those at ceramic abutments (Sailer et al. 2009). The unnatural bluish appearance causing aesthetic problems stems from the thin soft tissue of the peri-implant, which is incapable of screening the reflective light from the metallic abutment surface (Yildirim et al. 2000). As an alternative to titanium, the aluminium oxide abutment was next introduced in 1994. However, the inferior mechanical properties (i.e., low ability to withstand fractures) of alumina were not sufficient to be used alone as an implant abutment. Therefore, high strength, durable ceramic zirconia was developed and used as an implant abutment later in the 1990s (Belser et al. 2004; Guazzato et al. 2004).

Ceramic abutments including zirconia are well known to be superior to metal 
abutments in terms of their aesthetics, which prevent the gingival discoloration that is common with metal abutments (Jung et al. 2007). In addition, the results of a recently published study showed that significantly fewer bacterial colonies were found on zirconia surfaces compared with titanium surfaces (Rimondini et al. 2002; Scarano et al. 2004). Moreover, the favourable soft and hard tissue reaction to zirconia was comparable to the reaction to titanium (Kohal et al. 2004). Clinically, a previous 4-year prospective study indicated that the success rate of zirconia abutments in the anterior dental region was $100 \%$ (Glauser et al. 2004). However, clinical studies on zirconia abutments, especially in posterior restorations and implant-supported fixed partial dentures, are still scarce (Bae et al. 2008).

The aim of this study was to compute the long-term clinical survival and complication rates of alumina-toughened zirconia abutments used for implant-supported restorations and to evaluate the effects of several clinical variables on these rates. In addition, whether the survival/complication rate would be affected by the type of prosthesis or by the location of its placement in the mouth were also discussed.

\section{Material and methods}

\section{Subjects}

This study was performed at the Department of Prosthodontics at Seoul National University Dental Hospital in Seoul, South Korea, from May 1998 through to September 2010. Eligible participants were adults aged 18 years or older with successfully osseointegrated implant fixtures. Exclusion criteria were pregnancy and radiation therapy involving the head and neck area. A total of 213 fixed prosthodontic patients were recruited. The mean age of the patients was 57 years (range: 2086 years). All patients were treated with implant-supported single-unit fixed dental prostheses (FDPs), multiunit FDPs without pontics, or multiunit FDPs with pontics at Seoul National University Dental Hospital. The institutional review board for the protection of human subjects reviewed and approved the research protocol (IRB054/06-10).

The number of restorations examined in this study was 328. The following clinical variables were investigated: restored area (anterior and posterior restorations), number of prosthodontic units (one unit and two units or over), type of prosthesis (single-unit FDPs, multiunit FDPs without pontics, and multi- unit FDPs with pontics), external hexagon implant systems, and patient gender (Table 1).

\section{Alumina-toughened zirconia abutments}

The all ceramic alumina-toughened zirconia abutments $\left(\right.$ ZirAce $^{\circledR}$, Acucera, Pocheon, Korea) used for this prospective clinical study were composed of alumina reinforced yttria and niobia co-doped tetragonal zirconia polycrystalline $\left(\mathrm{Al}_{2} \mathrm{O}_{3} / \mathrm{Y}(\mathrm{Nb})-\mathrm{TZP}\right)$. This composite is known to be free of low temperature degradation during the ageing process and has $700 \mathrm{MPa}$ biaxial flexural strength and 8.1 $\mathrm{MPa} \cdot \mathrm{m}^{1 / 2}$ fracture toughness (Kim et al. 2000). Such properties facilitate procedures in the mouth and the laboratory using high speed diamond burs or low speed diamond wheels for adjusting into the final shape. In addition to this, abutments are light yellow in colour, similar to the natural teeth, adding to their desirability in aesthetics. The coefficient of thermal expansion of alumina-toughened zirconia is approximately $9.92 \times 10^{-6} /{ }^{\circ} \mathrm{C}$ and veneer porcelain for zirconia can be applied on the abutment directly (Lee et al. 2002).

\section{Clinical procedures}

After a certain period of healing time for external hexagon type implant fixtures, an impression was taken at the implant fixture level and master casts were fabricated. The appropriate dimensions of the prefabricated alumina-toughened zirconia abutments were selected according to the fixture diameter, soft tissue height, position and shape of adjacent teeth, and inter arch distance. Adjustment of the prefabricated abutment into the final contour with high speed diamond burs under copious water spray was performed. Next, the superstructure was fabricated with gold alloys or zirconia depending on the clinical situation for cementation type of prosthesis. The modified alumina-toughened zirconia abutments were screw-tightened to the implant fixtures with a torque of 30 $35 \mathrm{Ncm}$. The definitive prostheses were permanently cemented onto the abutments with resin-modified glass ionomer cement (Fujicem, GC, Tokyo, Japan). In some cases involving single tooth prostheses that were retained by screws, the alumina-toughened zirconia abutment was directly overlaid with veneer porcelain for zirconia and was screwtightened with a torque force of $35 \mathrm{Ncm}$ onto the fixtures.

\section{Survival and complication rates}

This prospective cohort study investigated the applicability of alumina-toughened zirconia abutments for implant-supported restora- tions using survival analysis, some advantages of which were mentioned in a previous study (Lee et al. 2010). Survival time was coded by the month after placement of the prosthesis. Implant abutment failure was coded as event data. Screw loosening, screw fracture, and abutment fracture were designated as complications in this study. Survival was classified as an abutment that functioned in the mouth regardless of the complications. Only a fractured abutment was excluded from survival data. Removal of the alumina-toughened zirconia abutment because of its fracture was designated as a failure. For subjects whose followup times ended without a failure event, the end status was recorded as "censored" because the actual duration of time to the failure event was unknown. Intact aluminatoughened zirconia abutments that were functioning properly during this investigation period were, therefore, coded as censored.

\section{Statistical analysis}

Odds ratio statistics were evaluated for all clinical variables. Kaplan-Meier survival curves were plotted, and the log rank test was used to identify the variables associated with the alumina-toughened zirconia abutment failure. Prognostic variables were identified with the Cox proportional hazard model using stepwise variable selection method.

Table 1. The clinical variables investigated in this study

\begin{tabular}{|c|c|}
\hline Variables & $\begin{array}{l}\text { Number of } \\
\text { restorations }\end{array}$ \\
\hline \multicolumn{2}{|l|}{ Restored area } \\
\hline Anterior & 60 \\
\hline Posterior & 268 \\
\hline \multicolumn{2}{|c|}{ Number of prosthetic units } \\
\hline One unit & 133 \\
\hline Two units or over & 195 \\
\hline \multicolumn{2}{|l|}{ Type of prosthesis } \\
\hline Single-unit FDPs & 133 \\
\hline $\begin{array}{l}\text { Multiunit FDPs } \\
\text { without pontics }\end{array}$ & 165 \\
\hline $\begin{array}{l}\text { Multiunit FDPs } \\
\text { with pontics }\end{array}$ & 30 \\
\hline \multicolumn{2}{|l|}{ Implant system } \\
\hline Osseotite ${ }^{*}$ & 15 \\
\hline USII & 42 \\
\hline TiUnite Mk III & 179 \\
\hline Hexplant $^{\S}$ & 39 \\
\hline Restore" & 53 \\
\hline \multicolumn{2}{|l|}{ Gender } \\
\hline Female & 165 \\
\hline Male & 163 \\
\hline \multicolumn{2}{|c|}{$\begin{array}{l}{ }^{*} \text { Biomet Korea Co., Ltd., Seoul, Korea } \\
{ }^{+} \text {Osstem, Seoul, Korea } \\
{ }^{ \pm} \text {Nobel Biocare AB, Göteborg, Sweden } \\
\text { 5WWarantec, Seoul, Korea } \\
\text { Lifecore Biomedical, LLC., Chaska, USA }\end{array}$} \\
\hline
\end{tabular}




\section{Results}

The average follow-up period was 3.6 years and the range was from 1 month to 12.8 years (Fig. 1). The age distributions for male (mean: 58 years) and female (mean: 55 years) patients did not significantly differ. Table 2 shows the coded events that occurred in this study. There were twenty restorations lost to follow-up, two restorations of which were not recalled because of patient's death. Follow-up of three FDPs were interrupted by traumatic injury, fracture of the implant fixture, and fixture disintegration. There were 31 fixed prostheses encountering the coded events that were designated as complications. Twenty-three restorations experienced abutment screw loosening, and two restorations underwent abutment screw fracture. The abutments of six restorations were fractured and classified as failures. Therefore, the number of survival restorations was 322 (Table 2).

The investigated clinical variables (restored area, number of prosthodontic units, type of

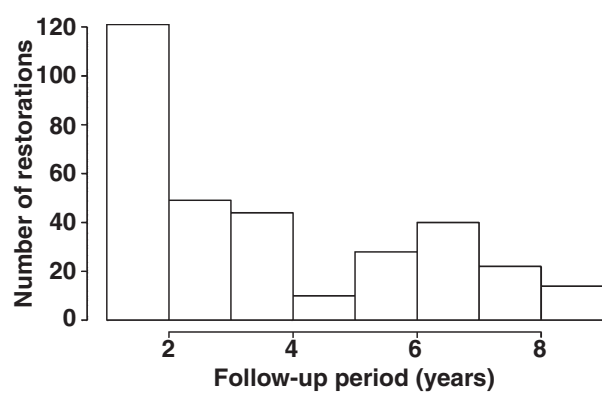

Fig. 1. The histogram shows distribution of the investigated restorations according to follow-up period. The number of restorations that were followed up for more than 8 years was displayed as one rod on the right.

Table 2. Demographic data and sample characteristics in this study

\begin{tabular}{lc}
\hline Coded events & $\begin{array}{l}\text { Number of } \\
\text { restorations }\end{array}$ \\
\hline Censored & 297 \\
No event & 274 \\
Lost to follow-up & 18 \\
Patient's death & 2 \\
Traumatic injury & 1 \\
Implant fixture fracture & 1 \\
Implant fixture disintegration & 1 \\
Complication & 31 \\
Abutment screw loosening & 23 \\
Abutment screw fracture & 2 \\
Fracture of the abutment & 6 \\
(failure) & 328 \\
Total & 322 \\
Survival* &
\end{tabular}

*Survival $=$ Total - Fracture of the abutment prosthesis, implant system, and gender) had no significant effect $(P>0.05)$ on survival of the alumina-toughened zirconia abutments. Furthermore, statistical comparison among the survival curves demonstrated no significant difference $(P>0.05)$ for the cumulative 5 -year survival rates of zirconia abutments in single-unit FDPs, multiunit FDPs without pontics, and multiunit FDPs with pontics. The survival rates were found to be $98.3 \%$, $99.2 \%$, and $96.1 \%$, respectively, for singleunit FDPs, multiunit FDPs without pontics, and multiunit FDPs with pontics.

Table 3 shows the results of Fisher's Exact tests for the effects of the clinical variables on the complications of the alumina-toughened zirconia abutments. The number of prosthodontic units and type of prosthesis had a significant association with complication rate. This study found four restorations in failure, and 22 restorations that experienced abutment screw loosening or fracture in single-unit FDPs. Only three multiunit FDPs without pontics had the complications of the screw loosening or fracture. Each group other than single-unit FDPs had one restoration that was designated as a failure. The complication rate of an alumina-toughened zirconia abutment was the highest in single restoration. The log rank test also indicated that the single restoration significantly increased the complication rate of the abutments $(P<0.001)$. Kaplan-Meier survival curves showed that the cumulative 5-year survival rate without any designated complications of alumina-toughened zirconia abutments in single restoration was $80.3 \%$, that is, the evaluated complication rate was $19.7 \%$, while those for multiunit FDPs without and with pontics were $96.1 \%$ and $96.2 \%$, respectively (Fig. 2). The Cox proportional hazard model showed that the number of prosthodontic units and the type of prosthesis were decisive factors for the complications of the alumina-toughened zirconia abutments.

Conditional inference trees with the survival function, estimated by Kaplan-Meier curves, are shown for every subgroup of patients identified (Fig. 3). The applied treestructured model is helpful for relating the risk of abutment failure to certain subgroups of patients. The type of prosthesis (singleunit FDPs, multiunit FDPs without pontics, multiunit FDPs with pontics) and the region of the dental restoration were the most important variables for abutment survival. Subjects treated with a single crown in the posterior region appeared to have the worst prognosis (Fig. 3).

\section{Discussion}

A total of 611 abutments were utilized for implant restorations, and a total of 328 restorations in 213 patients, consisting of 133 implant-supported single-unit FDPs, 165 multiunit FDPs without pontics, and 30 multiunit FDPs with pontics, were investigated. None of the investigated clinical variables had significant influence on survival of the alumina-toughened zirconia abutments. However, complication rates of screw loosening, screw fracture, and abutment fracture were shown to be significantly associated with the number of prosthodontic units and type of prosthesis.

The present study demonstrated successful use of alumina-toughened zirconia implant abutments for single and multiple restorations with high survival rates (more than 95\%) during the follow-up period. The promising clinical use of zirconia implant abutments for the support of single crowns was shown in a previous study, where two-thirds of the restorations replaced incisors and canines, and the remaining one-third of the restorations replaced premolars. However, there were no molar restorations in this study (Glauser et al. 2004). The present study, in contrast, evaluated the outcome of alumina-toughened zirconia abutments when they were used in the posterior (molar) area as well as the anterior area. The results indicated that the abutments can be successfully employed in both regions. These clinically important results are supported by additional studies that evaluated zirconia frameworks in high-loaded areas and also showed promising outcomes (Raigrodski et al. 2006; Sailer et al. 2007; Molin \& Karlsson 2008). Similarly, a meta-analysis found that the cumulative 5 -year survival rate was $99.1 \%$ for single ceramic abutments, and that the cumulative 5 -year rate with no complications was about $93 \%$ for both anterior and posterior restorations (Jung et al. 2008).

The present study showed the low complication rates of alumina-toughened zirconia abutments in multiunit FDPs with only a few incidences of screw loosening, screw fracture, and abutment fracture. The results were similar to those of previous studies that evaluated metal abutments (Jemt \& Lekholm 1993; Johansson \& Ekfeldt 2003). Multiple connected restorations appeared to be protected from complications by "tripodization", even in the high functional loading areas (e.g., molar regions) (Jemt et al. 1992; Jemt \& Lekholm 1993). Evaluation of the complication rate in the current study, however, dem- 
Table 3. Complication rate, exact test significance, and odds ratio statistics for zirconia implant abutments by clinical variables

\begin{tabular}{|c|c|c|c|c|c|c|c|}
\hline Variable & Censored $N(\%)$ & $\begin{array}{l}\text { Abutment screw } \\
\text { loosening and } \\
\text { fractureN }(\%)\end{array}$ & Failure $N(\%)$ & Total & Exact test significance & \multicolumn{2}{|c|}{ Odds ratio $(95 \% \mathrm{Cl})$} \\
\hline \multicolumn{8}{|l|}{ Restored area } \\
\hline Anterior & 58 & 1 & 1 & 60 & 0.088 & 1 & \\
\hline Posterior & 239 & 24 & 5 & 268 & & 3.51 & $(0.85,31.21)$ \\
\hline \multicolumn{8}{|c|}{ Number of prosthetic units } \\
\hline One unit & 107 & 22 & 4 & 133 & $<0.001^{\ddagger}$ & 1 & \\
\hline Over two units & 190 & 3 & 2 & 195 & & 0.11 & $(0.03,0.30)$ \\
\hline \multicolumn{8}{|l|}{ Type of prosthesis ${ }^{*}$} \\
\hline Single & 107 & 22 & 4 & 133 & $<0.001^{\ddagger}$ & 7.00 & $(1.05,298.34)$ \\
\hline FDPs without pontics & 161 & 3 & 1 & 165 & & 0.72 & $(0.07,36.69)$ \\
\hline FDPs with pontics & 29 & 0 & 1 & 30 & & 1 & \\
\hline \multicolumn{8}{|l|}{ Implant system ${ }^{\dagger}$} \\
\hline USII & 40 & 2 & 0 & 42 & 0.418 & 0.33 & $(0.02,5.01)$ \\
\hline TiUnite Mk III & 164 & 12 & 3 & 179 & & 0.60 & $(0.12,5.94)$ \\
\hline Hexplant & 33 & 3 & 3 & 39 & & 1.18 & $(0.18,13.41)$ \\
\hline Restore & 47 & 6 & 0 & 53 & & 0.83 & $(0.13,9.38)$ \\
\hline Osseotite & 13 & 2 & 0 & 15 & & 1 & \\
\hline \multicolumn{8}{|l|}{ Gender } \\
\hline Female & 145 & 16 & 4 & 165 & 0.130 & 1 & \\
\hline Male & 152 & 9 & 2 & 163 & & 0.53 & $(0.22,1.2)$ \\
\hline
\end{tabular}

onstrated that care must be taken in the use of an alumina-toughened zirconia abutment for a single molar restoration. Screw loosening appeared to be the major complication for an implant-supported single crown. Screw loosening was found in $7.0 \%$ of the restorations (23 restorations) during the follow-up period, while abutment fracture was found in only $1.8 \%$ of the restorations (six restorations). Several studies documented clinical possibilities for incidences of screw loosening and found that loosening generally occurs when the functional loading of the restoration causes a slight rotational freedom between the implant head and the abutment (Jemt \& Lekholm 1993; Jemt \& Pettersson

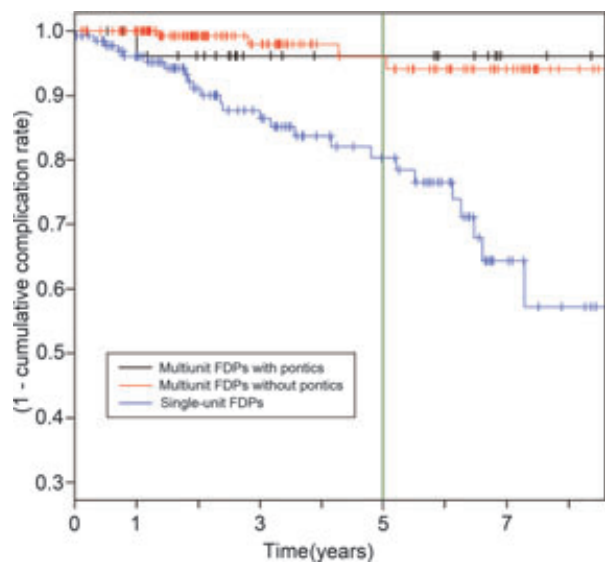

Fig. 2. Survival curves without any designated complications were tested for statistical difference $(P<0.001)$. Survival with no designated complications is expressed as subtracting the cumulative complication rate from 1 (y-axis). The green vertical line represents 5 years.
1993; Johansson \& Ekfeldt 2003). The results of the current study indicated that screw loosening occurred primarily in the posterior region, reflecting the high functional loading in this region. Moreover, a previous study reported that abutment screw loosening was the most frequent technical complication with single crown restorations, occurring at an estimated cumulative incidence of $5.1 \%$ (95\% confidence interval: $3.3-7.7 \%$ ) after 5 years (Jung et al. 2008). This finding is in line with the results of the present investigation. In contrast, neither abutment screw loosening nor abutment screw fracture occurred during 1-3-year follow-up periods in two additional recent studies (Zembic et al. 2009; Nothdurft \& Pospiech 2010). Furthermore investigation is required to compare the interface and screw mechanics of zirconia abutments with titanium implants, although the high strength and durability of zirconia and alumina-toughened zirconia compensate at least in part for their brittleness.

Another critical factor for successful implant restoration is the quality of the attachment that forms between the mucosa and the abutment surface (Abrahamsson et al. 1998). No remarkable inflammatory or otherwise disadvantageous tissue responses were observed around the alumina-toughened zirconia abutments, although no systematic quantitative evaluation was performed in this study. The previous 1-year clinical report on the biological stability of alumina-toughened zirconia abutments also demonstrated that the hard and soft tissue responses around the abutments were stable (Bae et al. 2008). Such a positive influence on the peri-implant soft tissue supports the clinical application of alumina-toughened zirconia abutments for both anterior and posterior implant-supported restorations.

All the investigated implant systems in the current study had external hexagon connections. Two-stage, external hexagon systems were previously reported to cause complications concerning the implant-abutment connection complex /Goodacre et al. 1999). In particular, a higher incidence of screw loosening and screw fracture was described to be associated with this type of implant-abutment connection (Walton \& MacEntee 1997). Single tooth applications with the external hexagon screw connection are exposed to more rigorous loading, providing an explanation for the frequent screw loosening observed for single implant-supported restorations (Rangert et al. 1997). However, no complications were reported for single zirconia abutments in the canine and posterior regions during the follow-up period of 3 years for two-stage, external hexagon systems in another study (Zembic et al. 2009). Furthermore studies will be required to clarify the survival rates and complications associated with implant-abutment connection systems, including internally connected complexes.

There were some limitations in this investigation. First, neither survival nor complication rate was analysed according to the materials of superstructure, which were gold 


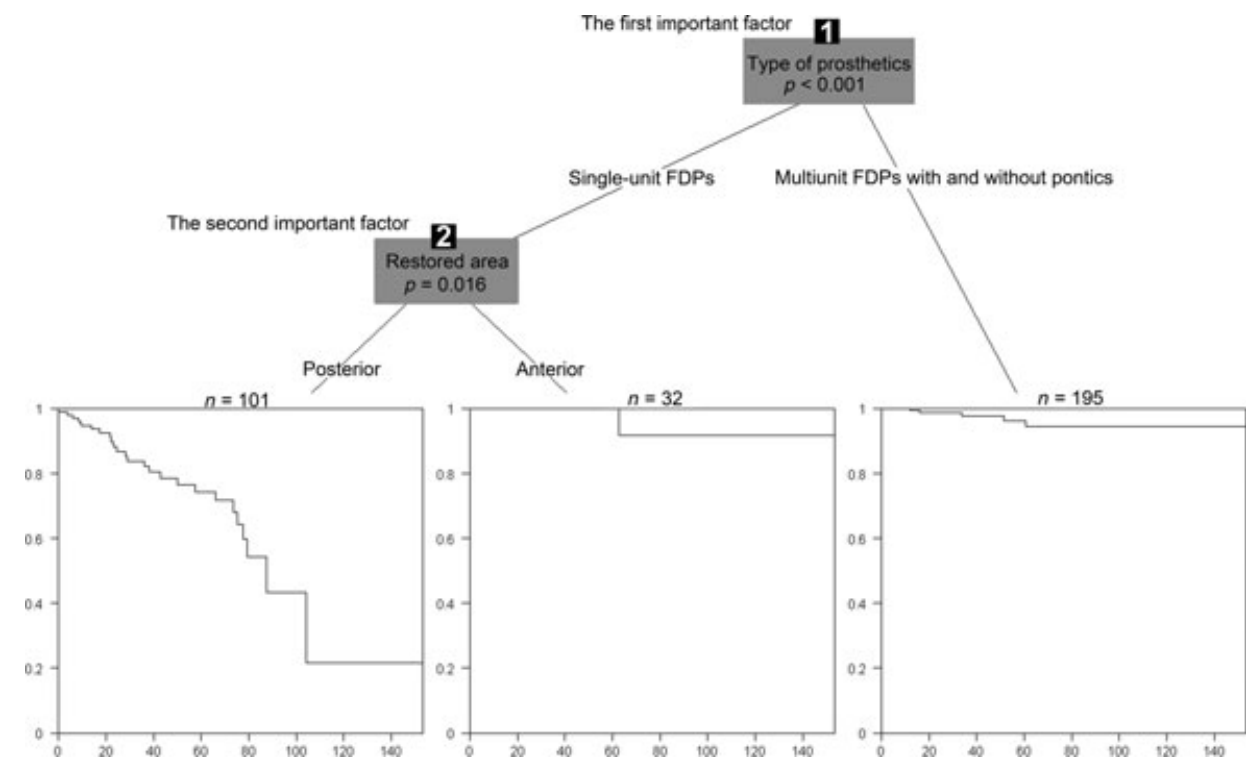

Fig. 3. Conditional inference tree with the survival function. The prosthesis type (single crown vs. multiple fixed restoration) was the most important variable. Subjects treated with single crown in posterior region showed the worst prognosis whereas multiple restorations (with or without pontics) indicates a good prognosis.

alloy and zirconia in this study. Such a nonstandardized condition can make the interpretation of the study outcomes different. Second, controlled trials are required to give more clear evidence of the alumina-toughened zirconia abutment than what this prospective cohort study gave.

In conclusion, prefabricated alumina-toughened zirconia abutments exhibit an excellent clinical profile for the long-term survival of

\section{References}

Abrahamsson, I., Berglundh, T., Glantz, P.O. \& Lindhe, J. (1998) The mucosal attachment at different abutments. Journal of Clinical Periodontology 25: 721-727.

Adell, R., Lekholm, U., Rockler, B. \& Branemark, P.I. (1981) A 15-year study of osseointegrated implants in the treatment of the edentulous jaw. International Journal of Oral Surgery 10: 387-416.

Andersson, B. (1995) Implants for single-tooth replacement. A clinical and experimental study on the branemark ceraone system. Swedish Dental Journal Supplement 108: 1-41.

Bae, K.H., Han, J.S., Seol, Y.J., Butz, F., Caton, J. \& Rhyu, I.C. (2008) The biologic stability of alumina-zirconia implant abutments after 1 year of clinical service: a digital subtraction radiographic evaluation. The International Journal of Periodontics and Restorative Dentistry 28: 137-143.

Belser, U.C., Schmid, B., Higginbottom, F. \& Buser, D. (2004) Outcome analysis of implant restorations located in the anterior maxilla: a review of the recent literature. The International Journal of Oral \&) Maxillofacial Implants 19(Suppl): 30-42.

Glauser, R., Sailer, I., Wohlwend, A., Studer, S., Schibli, M. \& Scharer, P. (2004) Experimental zirconia abutments for implant-supported singletooth restorations in esthetically demanding fixed restorations. These abutments appear to offer sufficient stability to support implant restorations at both anterior and posterior areas. However, considering the complications, including screw loosening and screw fracture as well as the abutment fracture, single tooth replacement with a zirconia abutment at the molar region may require special care and attention.

regions: 4-year results of a prospective clinical study. The International Journal of Prosthodontics 17: 285-290.

Goodacre, C.J., Kan, J.Y. \& Rungcharassaeng, K. (1999) Clinical complications of osseointegrated implants. The Journal of Prosthetic Dentistry 81: 537-552.

Guazzato, M., Albakry, M., Ringer, S.P. \& Swain, M.V. (2004) Strength, fracture toughness and microstructure of a selection of all-ceramic materials. Part ii. Zirconia-based dental ceramics. Dental Materials 20: 449-456.

Jemt, T. \& Lekholm, U. (1993) Oral implant treatment in posterior partially edentulous jaws: a 5-year follow-up report. The International Journal of Oral 4 Maxillofacial Implants 8: 635-640.

Jemt, T., Linden, B. \& Lekholm, U. (1992) Failures and complications in 127 consecutively placed fixed partial prostheses supported by branemark implants: from prosthetic treatment to first annual checkup. The International Journal of Oral \&) Maxillofacial Implants 7: 40-44.

Jemt, T. \& Pettersson, P. (1993) A 3-year follow-up study on single implant treatment. Journal of Dentistry 21: 203-208.

Johansson, L.A. \& Ekfeldt, A. (2003) Implant-supported fixed partial prostheses: a retrospective
Acknowledgement: This research was supported by Basic Science Research Program through the National Research Foundation of Korea (NRF) funded by the Ministry of Education, Science and Technology (2011-0024170 \& R01-2007-00010977-0). study. The International Journal of Prosthodontics 16: 172-176.

Jung, R.E., Pjetursson, B.E., Glauser, R., Zembic, A., Zwahlen, M. \& Lang, N.P. (2008) A systematic review of the 5-year survival and complication rates of implant-supported single crowns. Clinical Oral Implants Research 19: 119-130.

Jung, R.E., Sailer, I., Hammerle, C.H., Attin, T. \& Schmidlin, P. (2007) In vitro color changes of soft tissues caused by restorative materials. The International Journal of Periodontics and Restorative Dentistry 27: 251-257.

Kim, D.J., Lee, M.H., Lee, D.Y. \& Han, J.S. (2000) Mechanical properties, phase stability, and biocompatibility of $(\mathrm{y}, \mathrm{nb})$-tzp/al(2)o(3) composite abutments for dental implant. Journal of Biomedical Materials Research 53: 438-443.

Kohal, R.J., Weng, D., Bachle, M. \& Strub, J.R. (2004) Loaded custom-made zirconia and titanium implants show similar osseointegration: an animal experiment. Journal of Periodontology 75 : 1262-1268.

Lee, S.J., Ahn, S.J., Lee, J.W., Kim, S.H. \& Kim, T.W. (2010) Survival analysis of orthodontic miniimplants. American Journal of Orthodontics and Dentofacial Orthopedics 137: 194-199. 
Lee, D.Y., Kim, D.J. \& Kim, B.Y. (2002) Influence of alumina particle size on fracture toughness of $/ y$, $\mathrm{nb})$-tzp/al2o3 composites. Journal of the European Ceramic Society 22: 2173-2179.

Molin, M.K. \& Karlsson, S.L. (2008) Five-year clinical prospective evaluation of zirconia-based denzir 3-unit fpds. The International Journal of Prosthodontics 21: 223-227.

Nothdurft, F. \& Pospiech, P. (2010) Prefabricated zirconium dioxide implant abutments for single-tooth replacement in the posterior region: evaluation of peri-implant tissues and superstructures after 12 months of function. Clinical Oral Implants Research 21: 857-865.

Pjetursson, B.E., Bragger, U., Lang, N.P. \& Zwahlen, M. (2007) Comparison of survival and complication rates of tooth-supported fixed dental prostheses (fdps) and implant-supported fdps and single crowns (scs). Clinical Oral Implants Research 18 (Suppl 3): 97-113.

Raigrodski, A.J., Chiche, G.J., Potiket, N., Hochstedler, J.L., Mohamed, S.E., Billiot, S. \& Mercante,
D.E. (2006) The efficacy of posterior three-unit zirconium-oxide-based ceramic fixed partial dental prostheses: a prospective clinical pilot study. The Journal of Prosthetic Dentistry 96: 237-244.

Rangert, B.R., Sullivan, R.M. \& Jemt, T.M. (1997) Load factor control for implants in the posterior partially edentulous segment. The International Journal of Oral e) Maxillofacial Implants 12: 360-370.

Rimondini, L., Cerroni, L., Carrassi, A. \& Torricelli, P. (2002) Bacterial colonization of zirconia ceramic surfaces: an in vitro and in vivo study. The International Journal of Oral e) Maxillofacial Implants 17: 793-798.

Sailer, I., Feher, A., Filser, F., Gauckler, L.J., Luthy, H. \& Hammerle, C.H. (2007) Five-year clinical results of zirconia frameworks for posterior fixed partial dentures. The International Journal of Prosthodontics 20: 383-388.

Sailer, I., Philipp, A., Zembic, A., Pjetursson, B.E., Hammerle, C.H. \& Zwahlen, M. (2009) A systematic review of the performance of ceramic and metal implant abutments supporting fixed implant reconstructions. Clinical Oral Implants Research 20(Suppl 4): 4-31.

Scarano, A., Piattelli, M., Caputi, S., Favero, G.A. \& Piattelli, A. (2004) Bacterial adhesion on commercially pure titanium and zirconium oxide disks: an in vivo human study. Journal of Periodontology 75: 292-296.

Walton, J.N. \& MacEntee, M.I. (1997) A prospective study on the maintenance of implant prostheses in private practice. The International Journal of Prosthodontics 10: 453-458.

Yildirim, M., Edelhoff, D., Hanisch, O. \& Spiekermann, H. (2000) Ceramic abutments-a new era in achieving optimal esthetics in implant dentistry. The International Journal of Periodontics and Restorative Dentistry 20: 81-91.

Zembic, A., Sailer, I., Jung, R.E. \& Hammerle, C.H. (2009) Randomized-controlled clinical trial of customized zirconia and titanium implant abutments for single-tooth implants in canine and posterior regions: 3-year results. Clinical Oral Implants Research 20: 802-808. 